\title{
Knowledge and attitude on infant oral health among graduating medical students in Nepal
}

\section{Dhital S', Pradhan $\mathrm{M}^{2}$, Ghimire $\mathrm{S}^{3}$, Roy $\mathrm{DK}^{4}$, Dahal $\mathrm{S}^{5}$}

'Shweta Dhital, Lecturer; ${ }^{2}$ Megha Pradhan, Assistant Professor; Department of Pedodontics and Preventive Dentistry, ${ }^{3}$ Siddharth Ghimire; ${ }^{4}$ Deepak Kumar Roy, Lecturer; Department of Conservative Dentistry and Endodontics, ${ }^{5}$ Sirjana Dahal, Lecturer, Department of Community and Public Health Dentistry, Kathmandu Medical College, Duwakot, Bhaktapur, Nepal.

\begin{abstract}
Background: Overall, children less than five years old are seen more by a physician than a dentist. Physician need more knowledge and skills to address children's oral health due to the prevalence of dental diseases, the racial and socioeconomic disparities in disease burden, and the restricted access to dental care for many children. Thus, integrating oral health disease prevention and promotion strategies into these medical professionals' practice becomes essential.

Objectives: The objective of this study was to evaluate the knowledge and attitude of graduating medical students of Nepal towards infant oral health.

Methods: A self-administered questionnaire included questions on knowledge and attitude regarding infant oral health was distributed to 180 final year MBBS students of Nepal. Data were collected and entered in Microsoft Excel sheet and analysis was done using Statistical Package for the Social Sciences (SPSS) software version 20.

Results: The mean age of the participants was $23.36 \pm 1.12$ years. Only $23.9 \%$ of them knew that dental caries is infectious and transmissible from mother to baby and $38.9 \%$ were aware of the association of poor maternal gum health and preterm, low birth weight baby. Almost $73.9 \%$ knew that gum pads should be cleaned regularly and $46.1 \%$ knew that first dental visit of a child should be as soon as the first tooth erupts.

Conclusion: This study shows that graduating medical students of Nepal were knowledgeable about some aspects of early childhood caries and infant oral health, but uncertain about other aspects like the association between poor maternal gum health and premature low birth weight babies.
\end{abstract}

Key words: Dental caries, Infant oral health, Medical students, Nepal.

DOI: https://doi.org/10.3126/jkmc.v8i4.32386

\section{INTRODUCTION}

T The American Academy of Pediatric Dentistry (AAPD) recognizes that infant oral health is the foundation upon which preventive education and dental care must be built to enhance the opportunity to prevent oral

Address for correspondence

\footnotetext{
Dr. Shweta Dhital

Lecturer, Department of Pedodontics and Preventive Dentistry

Kathmandu Medical College Teaching Hospital

Duwakot, Bhaktapur, Nepal

E-mail: shwetadhital@gmail.com

ORCID:https://orcid.org/0000-0002-7786-9869

Co-Authors

Dr. MeghaPradhan: https://orcid.org/0000-0003-3381-3342

Dr. SiddharthGhimire: https://orcid.org/0000-0003-2687-7209

Dr. Deepak Kumar Roy:https://orcid.org/0000-0001-5057-7922

Dr. Sirjana Dahal:https://orcid.org/0000-0002-0536-1230
}

diseases over a lifetime'. AAPD defines early childhood caries as the presence of one or more decayed (noncavitated or cavitated lesions), missing (due to caries), or filled tooth surfaces in any primary tooth in a child 71 month of age or younger ${ }^{2}$. In primary teeth, dental caries is a preventable and reversible disease if treated in early stages. When left untreated, they can lead to a range of consequences, including: pain, bacteremia, alteration in growth and development, premature tooth loss, speech disorder, increase in treatment costs, loss of confidence, and negatively affect successor permanent teeth $^{3}$. Pediatricians and family physicians have the opportunity to affect the oral health of children because of their early and frequent contact during well-child and chronic condition visits. However, studies show they are not well informed about dental health and do not appropriately refer children with dental disease $\mathrm{d}^{4}$. 
This study was conducted to evaluate the knowledge and attitude of graduating medical students of Nepal towards infant oral health.

\section{METHODOLOGY}

This descriptive cross-sectional study was conducted among 180 final year MBBS students of medical colleges of Nepal from $15^{\text {th }}$ January 2019 to $15^{\text {th }}$ August 2019 after obtaining ethical clearance from institutional review board of Kathmandu Medical College, Sinamangal (Ref no.: 080820112). Six medical colleges of Nepal (two colleges affiliated to Tribhuwan University, two colleges affiliated to Kathmandu University, B.P. Koirala Institute of Health Sciences and Patan Academy of Health Sciences) were randomly selected by lottery method. Fifty final year MBBS students from Tribhuwan University, 55 from Kathmandu University, 40 from B.P. Koirala Institute of Health Sciences and 35 from Patan Academy of Health Sciences were selected by convenience sampling method.

Students who agreed to participate were included in the study after obtaining written informed consent. Students with known psychosocial problem like depression and bipolar disorder were not included in this study. The sample size was calculated using data of similar study ${ }^{4}$ using a formula, $\mathrm{n}=4 \mathrm{pq} / \mathrm{l} \wedge 2$ (Where $\mathrm{n}=$ Sample size, $\mathrm{p}$ $=$ Prevalence of $81, q=1-p, I=$ Margin of error, placing $I$ as $10 \%$ of $p)$.

A self-administered questionnaire having questions regarding infant dental anatomy, early childhood caries, maternal association, preventive strategies of early childhood caries and fluorides were used to assess the knowledge and attitudes on infant oral health of graduating medical students. Pre-testing was done among $10 \%$ of the sample from Kathmandu Medical College before starting the study. Those involved in pretesting were not included in the final sample. Face and content validity of the questionnaire were tested. Testretest reliability was done. A questionnaire form was distributed to the randomly selected participants and the filled form was collected for data analysis. Data were entered in Microsoft Excel Sheet and statistical analysis was done in Statistical Package for the Social Sciences (SPSS) version 20. Descriptive statistical analysis was done using mean, proportion and percentage.

\section{RESULTS}

A total of 180 students participated in the study with the mean age of $23.36 \pm 1.12$ years, among them $57.2 \%$ of participants were male and $42.8 \%$ were female. Only $37.8 \%$ students had received information about infant oral health from theoretical classes. In this study, 30\% of respondents knew that dental arches of newborn are called gum pads. First tooth erupts at the age of 5-6 months was a fact known by $84.4 \%$ of the respondents. About three-fourth of the respondents (73.3\%) knew premolars are absent in deciduous dentition. About 63.3\% knew natal teeth are present at birth and 38.3\% knew natal teeth are associated with Riga-fede disease (Table 1). Regarding early childhood caries, $48.3 \%$ of them considered Streptococcus mutants as the causative organism for early childhood caries and 33.3\% considered the right time for cessation of demand feeding is at the age of 6 months. Almost $24.4 \%$ of the medical students knew that the oral cavity of a newborn is free of bacteria (Table 2). In context to maternal association and early childhood caries, only $23.9 \%$ of the participants knew that dental caries is infectious and transmissible from mother to baby. Nearly $38.9 \%$ of the participants were aware of the association of poor maternal gum health and preterm, low birth weight baby. In a total, $82.2 \%$ felt that counseling to prevent early childhood caries in infants in the antenatal period is beneficial. Similarly, $84.4 \%$ replied that counseling on feeding and weaning practices decrease early childhood caries (Table 3). Around three-fourth (73.9\%) of the participants were aware about the fact that the gum pads should be cleaned regularly. About half of the respondents (49.4\%) knew that the correct time to start cleaning of teeth is immediately after the eruption of first tooth. Almost $79.4 \%$ of the participants replied the best time to brush the teeth is before going to bed. However, $46.1 \%$ of the participants knew that the first dental visit of a child should be as soon as the first tooth erupts (Table 4). Altogether $79.4 \%$ of the participants knew that fluoride decreases dental caries, $46.1 \%$ knew the beneficial level of fluoride in water and $42.8 \%$ knew that the corporation water supply is not fluoridated. About $29.4 \%$ wouldn't recommend fluoride toothpaste to toddlers whereas $45.6 \%$ would recommend fluoride toothpaste to toddlers (Table 5). 
Table 1: Responses regarding Infant Dental Anatomy

\begin{tabular}{|c|c|c|c|c|}
\hline S.N. & Cognitive Variables & Responses & $n(180)$ & $\%$ \\
\hline \multirow{3}{*}{1.} & \multirow{3}{*}{ Dental arches of newborn are called } & Gum-pads* & $54^{*}$ & $30^{*}$ \\
\hline & & Alveolar ridge & 54 & 30 \\
\hline & & I don't know & 72 & 40 \\
\hline \multirow{3}{*}{2.} & \multirow{3}{*}{ First tooth erupts in the oral cavity } & 5-6 months* & $152^{*}$ & $84.4^{*}$ \\
\hline & & 5-6 years & 12 & 6.7 \\
\hline & & I don't know & 16 & 8.9 \\
\hline \multirow{4}{*}{3.} & \multirow{4}{*}{ Tooth absent in deciduous dentition } & Canine & 11 & 6.1 \\
\hline & & Premolar* & $132^{*}$ & $73.3^{*}$ \\
\hline & & Molar & 23 & 12.8 \\
\hline & & I don't know & 14 & 7.8 \\
\hline \multirow{3}{*}{4.} & \multirow{3}{*}{ Natal teeth are present at } & Birth* & $114^{*}$ & $63.3^{*}$ \\
\hline & & Within one month of birth & 32 & 17.8 \\
\hline & & I don't know & 34 & 18.9 \\
\hline \multirow{3}{*}{5.} & \multirow{3}{*}{ Natal tooth causes } & No problem & 41 & 22.8 \\
\hline & & Riga-fede disease* & $69 *$ & $38.3^{*}$ \\
\hline & & I don't know & 70 & 38.9 \\
\hline
\end{tabular}

*Right Answer

Table 2: Early Childhood Caries (Awareness of Respondents on Early Childhood Caries)

\begin{tabular}{|c|c|c|c|c|}
\hline S.N. & Cognitive Variables & Responses & n (180) & $\%$ \\
\hline \multirow{3}{*}{1.} & \multirow{3}{*}{ Oral cavity of newborn is free of Bacteria } & Yes* $^{*}$ & $44^{*}$ & $24.4^{*}$ \\
\hline & & No & 114 & 63.3 \\
\hline & & I don't know & 22 & 12.2 \\
\hline \multirow{3}{*}{2.} & \multirow{3}{*}{$\begin{array}{l}\text { Cessation of demand feeding should be done at } \\
\text { the age of }\end{array}$} & 6 months* $^{*}$ & $60^{*}$ & $33.3^{*}$ \\
\hline & & 1 year & 48 & 26.7 \\
\hline & & 2 years & 72 & 40.0 \\
\hline \multirow{3}{*}{3.} & \multirow{3}{*}{ Most common dental disease } & Dental caries* & $158^{*}$ & $87.8^{*}$ \\
\hline & & Mobile tooth & 6 & 3.3 \\
\hline & & Gum bleeding & 16 & 8.9 \\
\hline \multirow{4}{*}{4.} & \multirow{4}{*}{ Causative organism of early childhood caries } & Lactobacillus & 53 & 29.4 \\
\hline & & Streptococcus mutans* & $87^{*}$ & $48.3^{*}$ \\
\hline & & Worms & 1 & 0.6 \\
\hline & & I don't know & 39 & 21.7 \\
\hline \multirow{4}{*}{5.} & \multirow{4}{*}{ Teeth first affected by early childhood caries } & Maxillary incisors* & $62^{*}$ & $34.4^{*}$ \\
\hline & & Mandibular incisors & 48 & 26.7 \\
\hline & & All teeth are equally affected & 37 & 20.6 \\
\hline & & I don't know & 33 & 18.3 \\
\hline
\end{tabular}

${ }^{*}$ Right Answer 


\section{Table 3: Maternal Association and Early Childhood Caries.}

\begin{tabular}{|c|c|c|c|c|}
\hline S.N. & Cognitive Variables & Responses & n (180) & $\%$ \\
\hline \multirow{3}{*}{1.} & \multirow{3}{*}{$\begin{array}{l}\text { Is dental caries infectious and transmissible } \\
\text { from mother? }\end{array}$} & Yes* & $43^{*}$ & $23.9^{*}$ \\
\hline & & No & 113 & 62.8 \\
\hline & & I don't know & 24 & 13.3 \\
\hline \multirow{3}{*}{2.} & \multirow{3}{*}{ Poor maternal gum health is associated to } & Premature, Low Birth Weight babies* & $70^{*}$ & $38.9^{*}$ \\
\hline & & Brushing during pregnancy & 24 & 13.3 \\
\hline & & I don't know & 86 & 47.8 \\
\hline \multirow{3}{*}{3.} & \multirow{3}{*}{$\begin{array}{l}\text { Is counseling to prevent early childhood } \\
\text { caries in infants in antenatal period is } \\
\text { beneficial? }\end{array}$} & Yes* & $148^{*}$ & $82.2^{*}$ \\
\hline & & No & 16 & 8.9 \\
\hline & & I don't know & 16 & 8.9 \\
\hline \multirow{3}{*}{4.} & \multirow{3}{*}{$\begin{array}{l}\text { Can counseling on feeding and weaning } \\
\text { practices decrease early childhood caries? }\end{array}$} & Yes* & $152^{*}$ & $84.4^{*}$ \\
\hline & & No & 3 & 1.7 \\
\hline & & I don't know & 25 & 13.9 \\
\hline
\end{tabular}

${ }^{*}$ Right Answer

Table 4: Preventive Strategies

\begin{tabular}{|c|c|c|c|c|}
\hline S.N. & Cognitive Variables & Responses & n (180) & $\%$ \\
\hline \multirow{3}{*}{1.} & \multirow{3}{*}{ Should gum pads be cleaned? } & Yes* & $133^{*}$ & $73.9^{*}$ \\
\hline & & No & 11 & 6.1 \\
\hline & & I don't know & 36 & 20.0 \\
\hline \multirow{3}{*}{2.} & \multirow{3}{*}{ Correct time to start cleaning of teeth } & 1 year after eruption of first tooth & 62 & 34.4 \\
\hline & & Immediately after eruption of first tooth* & $89 *$ & $49.4^{*}$ \\
\hline & & 3 years after eruption of first tooth & 29 & 16.1 \\
\hline \multirow{3}{*}{3.} & \multirow{3}{*}{ Best time to brush the teeth } & Morning & 31 & 17.2 \\
\hline & & Before going to bed* & $143^{*}$ & $79.4^{*}$ \\
\hline & & I don't know & 6 & 3.3 \\
\hline \multirow{3}{*}{4.} & \multirow{3}{*}{$\begin{array}{l}\text { When should a toothbrush be } \\
\text { recommended }\end{array}$} & After the tooth starts to decay & 17 & 9.4 \\
\hline & & Once the tooth starts to erupt* & $142^{*}$ & $78.9^{*}$ \\
\hline & & I don't know & 21 & 11.7 \\
\hline \multirow{3}{*}{5.} & \multirow{3}{*}{ First dental visit should be } & As soon as the first tooth erupts* & $83^{*}$ & $46.1^{*}$ \\
\hline & & After the child turns 3 years & 58 & 32.2 \\
\hline & & I don't know & 39 & 21.7 \\
\hline
\end{tabular}

${ }^{*}$ Right Answer

Table 5: Fluoride

\begin{tabular}{|c|c|c|c|c|}
\hline S.N. & Cognitive Variables & Responses & $n(180)$ & $\%$ \\
\hline \multirow{3}{*}{1.} & \multirow{3}{*}{ Does fluoride decrease dental caries } & Yes* & $143^{*}$ & $79.4^{*}$ \\
\hline & & No & 25 & 13.9 \\
\hline & & I don't know & 12 & 6.7 \\
\hline \multirow{3}{*}{2.} & \multirow{3}{*}{ Beneficial level of fluorides in water is } & 1 parts per million* & $83^{*}$ & $46.1^{*}$ \\
\hline & & 2 parts per million & 56 & 31.1 \\
\hline & & I don't know & 41 & 22.8 \\
\hline \multirow{3}{*}{3.} & \multirow{3}{*}{ Is corporation water supply fluoridated } & Yes & 56 & 31.1 \\
\hline & & $\mathrm{No}^{*}$ & $77^{*}$ & $42.8^{*}$ \\
\hline & & I don't know & 47 & 26.1 \\
\hline \multirow{3}{*}{4.} & \multirow{3}{*}{$\begin{array}{l}\text { Can fluoride toothpaste be used for } \\
\text { toddlers }\end{array}$} & Yes & 82 & 45.6 \\
\hline & & $\mathrm{No}^{*}$ & $53^{*}$ & $29.4^{*}$ \\
\hline & & I don't know & 47 & 26.1 \\
\hline
\end{tabular}

*Right Answer 


\section{DISCUSSION}

Nearly, all children have a medical visit by their first birthday, which when compared to the dental visit gives a ratio of $250: 1^{5}$. Because of the frequent contact of the pediatricians with family members for routine preventive visits in the child's first few years of life, they are in an ideal and unique position to advise families about the prevention of oral diseases in their children ${ }^{6}$. The lack of oral health education in medical school and residency curricula has been well documented. Physicians report not receiving sufficient instruction on oral health care ${ }^{7}$.

In the present study, only $38.3 \%$ of the medical students knew the association between natal teeth and Riga-fede disease which is comparable with the study done in Kerala, India ${ }^{4}$ which reported $32 \%$ knew the association between natal teeth and Riga-fede disease.

In the present study, $48.3 \%$ of medical students were aware that the causative organism for early childhood caries is Streptococcus mutants which is comparable with the study done in Bangalore, India $(48.5 \%)^{8}$ and higher than that of a study done in Kerala, India (10\%) 4 . About $23.9 \%$ of medical students agreed that dental caries is infectious and transmissible from mother which is higher than a study done in Bangalore, India (19.5\%), study done in Lagos, Nigeria $(14.7 \%)^{9}$ and a study done in Kerala, India (9\%) ${ }^{4}$ and lower than a study done in Bagalkot and Bangalore, India $(47 \%)^{10}$. About 33.3\% agreed that cessation of demand feeding should be done at the age of six months, which is higher than the study done in Bangalore, India $(18.4 \%)^{8}$, and lower than the study done in two universities of Illinois campuses $(49.4 \%)^{7}$. To relate the association between periodontal disease and pre-term/low birth weight there is a hypothesis that explains the indirect mode of disease transfer through translocation of bacteria or bacterial products in the systemic circulation. The presence of transient bacteremia occurs in patients suffering from marginal periodontitis or with gingival diseases, and there is a possibility for those bacteria and their products to reach the placental membranes hematogenously and provide the inflammatory effect to induce preterm labor $^{11}$. About $38.9 \%$ of the medical students knew the association between poor maternal gum health and premature low birth weight babies which is lower than a study done in Kerala, India (48\%) ${ }^{4}$.

The majority of pregnant women are deprived of proper instructions during pregnancy regarding oral health, even though this is a phase of increased acceptance of instructions that should be used as an opportunity to introduce preventive programs ${ }^{4}$. In the present study, majority of the $(82.2 \%)$ respondents felt that the counseling in antenatal period is beneficial to prevent early childhood caries in infants which is higher than the studies done in Bangalore, India (70.2\%) ${ }^{8}$ and Bagalkot and Bangalore, India $(60 \%)^{10}$. Regarding preventive strategies, about $73.9 \%$ of the respondents agreed that gum pads should be cleaned which is higher than the studies done in Kerala, India (32\%) ${ }^{4}$, Bagalkot and Bangalore, India $(25 \%)^{10}$ and Lagos, Nigeria $(23 \%)^{9}$ but lower than the study done in Bangalore, India $(79.4 \%)^{8}$. According to the American Academy of Pediatric Dentistry, a child's first visit to the dentist should occur at the time of the eruption of the first tooth and no later than 12 months of age ${ }^{12}$. However, $46.1 \%$ participants in the present study said that the first dental visit should be recommended as soon as the first tooth erupts which is higher than the study done in Kerala, India $(40 \%)^{4}$ whereas lower than the studies done in Bangalore, India $(65.2 \%)^{8}$ and Bagalkot and Bangalore, India $(52.5 \%)^{10}$. Regarding fluoride, only $29.4 \%$ respondents believed that fluoridated toothpaste should not be used for toddlers which is higher than the study done in Kerala, India $(4 \%)^{4}$ and lower than the study done in Bangalore, India $(48.7 \%)^{8}$.

\section{CONCLUSION}

This study hasidentified that graduating medical students of Nepal lack adequate knowledge on infant oral health. They were knowledgeable about some aspects of early childhood caries and infant oral health, but uncertain about the association between poor maternal gum health and premature low birth weight babies and the use of fluoridated toothpaste in toddlers. Hence, there is need to increase the knowledge of graduating medical students through effective strategies such as training and continuing medical education in infant oral health in medical school. Medical students are future public figures who are closely related to society for providing knowledge on different oral and dental disease prospect to the community. So, further studies with more sample are recommended to carry out such researches on knowledge and attitude on infant oral health among graduating medical students in Nepal. Limitation of the study was the use of convenience sampling method for selection of final year student's due to which the study cannot be generalized to all the medical students of Nepal. 


\section{REFERENCES}

1. American Academy of Pediatric Dentistry. Perinatal and infant oral health care. The Reference Manual of Pediatric Dentistry[Internet]. 2016; 228-232 [cited 2019 June 19][FullText]

2. Drury TF, Horowitz AM, Ismail Al, Maertens MP, Rozier RG, Selwitz RH. Diagnosing and reporting early childhood caries for research purposes. A Report of a Workshop Sponsored by the National Institute of Dental and Craniofacial Research, the Health Resources and Services Administration, and the Health Care Financing Administration. J Public Health Dent. 1999; 59(3):192-7[DOI]

3. Alazmah A. Early childhood caries: a review. J Contemp Dent Pract. August 2017;18(8):732-737 [DOI]

4. Kumari RN, Sheela S, Sarada PN. Knowledge and attitude on infant oral health among graduating students in Kerela. J Indian Soc Pedod Prev Dent. 2006; 24(4):173-176 [DOI]

5. Long CM, Quinonez RB, Beil HA, Close K, Myers LP, Vann WF Jr., et al. Pediatricians' assessments of caries risk and need for a dental evaluation in preschool aged children. BMC Pediatr. 2012; 12:49.[DOI]

6. Mallick S, Balaji SK, Chandraiah M, Krishnamurthy A, Ganesh SA, Venkatesh RS. Knowledge, practice, and training of pediatricians about early childhood caries in Bhubaneswar. J Indian Assoc Public Health Dent. 2016; 14:313-7. [DOI]
7. Chung MH, Kaste LM, Koerber A, Fadavi S, Punwani I. Dental and medical students' knowledge and opinions of infant oral health. J Dent Educ. May 2006; 70(5):511-517. [PMID]

8. Bhat PK, Aruna CN, Badiyani BK, Alle R. Knowledge and attitude on infant oral health among graduating medical students in Bangalore city, India.[Internet] JIMSA. 2014 [cited 2019 June 19] ;27:13-14. [FullText]

9. Olatosi OO, Iwuala SO, Ojewola RW, Chukwudifu $\mathrm{N}$, Oredugba FA, Sote EO. Undergraduate medical students' knowledge and attitude on early childhood caries and infant oral health. J Pediatr Dent. 2016; 4:8-13.[DOI]

10. Shivaprakash PK, Elango I, Baweja DK, Noorani $\mathrm{HH}$.The state of infant oral healthcare knowledge and awareness:Disparity among parents and healthcare professionals [Internet] J Indian Soc Pedod Prev Dent. 2009 [cited 2019 June 19]; 27:3943.[FullText]

11. Lopez NJ, Da Silva I, Ipinza J, Gutierrez J. Periodontal therapy reduces the rate of preterm low birth weight in women with pregnancy-associated gingivitis. J Periodontol. 2005; 76:2144-53. [DOI]

12. American Academy of Pediatric Dentistry, Periodicity of Examination, Preventive Dental Services, Anticipatory Guidance/Counseling, and Oral Treatment for Infants, Children, and AdolescentsReference Manual [Internet].2018 [cited 2019 June 19]; 40:194-203. [FullText] 